\title{
Revisão do gênero neotropical Apophorhynchus Williston (Diptera, Ropalomeridae)
}

\author{
Ana Paula Marques-Costa ${ }^{1,2}$, Rosaly Ale-Rocha ${ }^{2}$
}

\begin{abstract}
'Departamento de Zoologia, Pós-Graduação em Entomologia, Universidade Federal do Paraná-UFPR. Caixa Postal 19020, 81531-980, Curitiba-PR, Brasil. apcm@ufpr.br.

${ }^{2}$ Coordenação de Pesquisas em Entomologia, Instituto Nacional de Pesquisas da Amazônia-INPA. Caixa Postal 478, 69011-970, Manaus-AM, Brasil. alerocha@inpa.gov.br.
\end{abstract}

\begin{abstract}
Revision of the neotropical genus Apophorhynchus Williston (Diptera, Ropalomeridae). The genus Apophorhynchus and the species A. flavidus Williston, 1895 and A. amazonensis Prado, 1966 are redescribed. One new species, A. brevipenis sp. nov., is described from Brazil (Amazonas). The three species are illustrated and keyed.
\end{abstract}

KEYWORDS. Distribution; identification key; new species; taxonomy.

RESUMO. Revisão do gênero neotropical Apophorhynchus Williston (Diptera, Ropalomeridae). O gênero Apophorhynchus e as espécies A. flavidus Williston, 1895 e A. amazonensis Prado, 1966 são redescritos. Uma espécie nova, A. brevipenis sp. nov. é descrita do Brasil (Amazonas). As três espécies são ilustradas e uma chave para espécies é fornecida.

PALAVRAS-CHAVE. Distribuição; chave de identificação; espécie nova; taxonomia.

A família Ropalomeridae compreende, atualmente, 30 espécies válidas distribuídas em oito gêneros (Steyskal 1967; Ramírez-García \& Hernández-Ortiz 1994; Marques \& Ale-Rocha 2004, 2005). É principalmente neotropical, ocorrendo desde o Sul dos Estados Unidos da América até o Norte da Argentina, com uma única espécie conhecida na Região Neártica, Rhytidops floridensis (Aldrich, 1932) (Steyskal, 1987). No Brasil foram registradas 25 espécies em seis gêneros (Steyskal 1967; Prado \& Papavero 2002; Marques \& Ale-Rocha 2004, 2005).

Apophorhynchus Williston, 1895 é um gênero de moscas castanhas, medindo de 7,9 a $10 \mathrm{~mm}$, com fronte ampla e pouco côncava, sem cerdas ocelar e pós-ocelar, face com tubérculo central pontiagudo, arista plumosa, escutelo sem cerdas de revestimento, geralmente com 1 par de cerdas apical e 1 par marginal destacados e pernas com fêmures moderadamente engrossados. Inclui duas espécies conhecidas: A. flavidus Williston, 1895, espécie-tipo, descrita a partir de duas fêmeas (síntipos), localidade-tipo Chapada dos Guimarães, Mato Grosso, Brasil e registrada para a Bolívia; A. amazonensis Prado, 1966, holótipo fêmea, proveniente de São Gabriel da Cachoeira, Amazonas, Brasil e registrada posteriormente para o Peru (Prado 1967; Steyskal 1967).

Este trabalho inclui, além da redescrição de $A$. amazonensis e A. flavidus, a descrição de A. brevipenis sp. nov. Apophorhynchus amazonensis é registrada pela primeira vez no Estado de Rondônia (Brasil) e no Departamento de Madre de Dios (Peru) e uma chave de identificação para fêmeas é fornecida. Não foi elaborada uma chave de identificação para machos porque apenas duas espécies, A. amazonensis e $A$. brevipenis sp. nov. têm os machos conhecidos e os mesmos podem ser facilmente distinguidos pela diagnose que precede a descrição, bem como pelos caracteres da terminália, cujos desenhos são fornecidos.

\section{MATERIAL E MÉTODOS}

Foram examinados 39 espécimes montados em alfinetes: 21 espécimes de $A$. amazonensis, 16 de $A$. brevipenis sp. nov. e 2 de $A$. flavidus. O abdome foi desprendido, para análise das estruturas da terminália. A terminália masculina foi aquecida em ácido láctico $85 \%$, por 15-30 minutos em média. A terminália feminina, por ser mais frágil, permaneceu em solução de hidróxido de potássio $10 \%$ a frio durante cerca de $24-48$ horas. Posteriormente, foi colocada em solução de ácido acético e lavada em água destilada. As peças foram acondicionadas em microtubos de plástico (4x10 mm), com glicerina, e afixados no alfinete do espécime. A asa foi destacada e mergulhada em xilol por algumas horas sendo, posteriormente, montada com bálsamo do Canadá, entre lamínulas e fotografada.

A terminologia empregada segue o trabalho de McAlpine (1981). As abreviaturas citadas no texto correspondem às seguintes instituições responsáveis pelo empréstimo do material: AMNH, “American Museum of Natural History”, New York; INPA, Instituto Nacional de Pesquisas da Amazônia, Manaus; MCZ, "Museum of Comparative Zoology", Cambridge; MPEG, Museu Paraense Emílio Goeldi, Belém; MZSP, Museu de Zoologia da Universidade de São Paulo, São Paulo; NMNH, "National Museum of Natural History", Washington, D. C.

A abreviatura reg. nov., citada na distribuição geográfica, significa novo registro. Na lista de material-tipo examinado, as informações que não constavam nas etiquetas dos espécimes foram acrescentadas e colocadas entre colchetes. 


\section{Apophorhynchus Williston, 1895}

Apophorhynchus Williston, 1895: 184; 1896: 280-281 (chave, ilustrações); Lindner, 1930: 125-126 (diagnose, chave); Malloch, 1941: 50 (diagnose); Prado, 1966: 213 e 248 (chave, diagnose); 1967: 73 (diagnose); Steyskal, 1967: 1 (catálogo); Prado \& Papavero, 2002: 1 (catálogo).

Espécie-tipo: Apophorhynchus flavidus Williston, 1895 (designação original).

Diagnose. Face com tubérculo central pontiagudo; arista plumosa; cerdas orbital, ocelar e pós-ocelar ausentes; verticais interna e externa presentes; gena curta; cerda supra-alar présutural ausente; escutelo sem cerdas de revestimento, geralmente com 1 par de cerdas apical e 1 par marginal destacados; 1 cerda na borda superior do espiráculo metatorácico; pernas com fêmures moderadamente engrossados; tíbias delgadas, tíbia posterior arqueada com 14 cerdas dorsais finas e longas; tergitos 2-5 com faixa estreita de polinosidade nas margens laterais e posterior.

Descrição (macho e fêmea). Cabeça: trapezoidal, fronte ampla, pouco côncava; cerdas orbital, ocelar e pós-ocelar ausentes; verticais interna e externa presentes; ocelos circundados por um triângulo de polinosidade dourada, que se alonga em direção a margem anterior da fronte; margens laterais ao triângulo com polinosidade prateada, visível ou não nas fêmeas, dependendo da incidência luminosa; face larga com tubérculo facial grande e pontiagudo nas fêmeas, mais estreita com tubérculo reduzido e levemente arredondado nos machos; órbita ocular com faixa muito estreita de polinosidade dourada; polinosidade esparsa, dourada ou prateada, entre e abaixo das antenas; artículos antenais cobertos por polinosidade dourada esparsa; pedicelo com várias cerdas na margem dorsal, uma mais destacada; arista plumosa, com ápice nu; gena curta, com faixa longitudinal de polinosidade dourada e cerdas curtas superiormente e mais longas inferiormente; palpo coberto com polinosidade dourada e esparsa nas faces dorsal e ventral.

Tórax: escuto com faixas de polinosidade dourada, cerdas de revestimento curtas e várias cerdas destacadas: 2 notopleurais, 1 supra-alar pós-sutural, 1 pós-alar, 1 intra-alar, 1 intra-pós-alar, 1 acrostical pós-sutural pré-escutelar; cerdas supra-alar pré-sutural e pós-pronotal ausentes. Escutelo com o dorso levemente convexo e polinosidade dourada nas laterais e na margem apical. Pleura com faixa de polinosidade dourada que se estende até o anepímero; 1 cerda anepisternal e 1 catepisternal destacadas; anepímero sem cerdas distintas; 1 cerda na borda superior do espiráculo metatorácico.

Asa: uniformemente enfuscada, amarelada a castanha, exceto na base, acima da álula, hialina; ápice das células $\mathrm{r}_{1} \mathrm{e}$ $r_{2+3}$ levemente mais escurecidos; última seção da $R_{4+5}$ quase reta; forquilha do setor radial e final da $\mathrm{Sc}$ aproximadamente à mesma distância da base da asa; última seção da M levemente convexa na metade basal; $\mathrm{CuA}_{2}$ arqueada, formando ângulo agudo com $\mathrm{A}_{1}$; álula pequena em relação aos demais gêneros (Figs. 28-30).
Pernas: fêmures mais robustos nos machos que nas fêmeas, principalmente o fêmur posterior; tíbias delgadas; tíbia anterior com 1 cerda subapical dorsal distintamente diferenciada; tíbia média com 2-3 cerdas grossas apicais ventrais e tíbia posterior arqueada, com 1-4 cerdas dorsais finas e longas.

Abdome: tergitos 2-5 com faixa estreita de polinosidade prateada ou dourada nas margens laterais e posterior (Fig. 1); esternitos cobertos por polinosidade pálida. Terminália feminina telescopada, membranosa na maior parte; esternito 6 com 5-7 cerdas na margem posterior; segmento 7 membranoso na maior parte; esternito 7 ausente, face ventral com 1-2 pares de cerdas; um espiráculo no segmento 6; epiprocto alongado, com 1 par de cerdas destacadas na porção basal (Figs. 16, 20, 24); hipoprocto com 1 par basal de cerdas e uma fenda mediana longitudinalmente, que não atinge o ápice (Figs. 17, 21, 25); cerco alongado, cerdoso, com cerdas maiores no ápice; espermateca cilíndrica, alongada, com finas estrias transversais e processo apical curto (Figs. 19, 23, 27). Esternito 5 do macho, retangular, com várias cerdas aleatoriamente distribuídas, maiores na região posterior, próximo à área membranosa. Terminália masculina: epândrio com expansão lateral na região posterior (Figs. 4, 11); cercos fusionados nos $2 / 3$ basais, cilíndricos e densamente cerdosos, com cerdas maiores no ápice; surstilos mais longos que os cercos, fusionados na base, com ápices afilados e curvados para dentro (Figs. 3-4, 10-11); parâmero bilobado, com pequenas cerdas no ápice; hipândrio com expansão lateral alongada e membranosa; gonópodo com 1 cerda longa destacada, inserida num tubérculo (Figs. 6-7, 13-14); edeago fortemente esclerotinizado, com ápice truncado e duas formações basais cônicas, fusionadas na região central da base (Figs. 6, 13); apódema do edeago com extremidade livre de margem arredondada; epifalo pequeno e fracamente esclerotinizado (Figs. 6, 13).

Comprimento do corpo: 7,9-10 mm.

Distribuição geográfica. Brasil, Bolívia e Peru.

Comentários. Difere dos demais gêneros pela ausência das cerdas orbital, ocular e pós-ocular; por ter uma cerda na borda superior do espiráculo metatorácico; os tergitos 2-5 com faixa estreita de polinosidade nas margens laterais e posterior. As espécies deste gênero podem ser separadas pelos diferentes padrões de coloração das pernas, e, principalmente, pela morfologia das terminálias masculina e feminina.

Chave para as espécies de Apophorhynchus Williston (fêmeas)

1. Polinosidade dos tergitos dourada; tergito 6 com 1-2 cerdas destacadas póstero-laterais (Fig. 24, 26); espermateca com processo apical grosso (Fig. 27) Apophorhynchus flavidus Williston

Polinosidade dos tergitos prateada; tergito 6 com fileira de 4-7 cerdas destacadas póstero-laterais (Figs. 18, 22); espermateca com processo apical fino (Figs. 19, 23) 


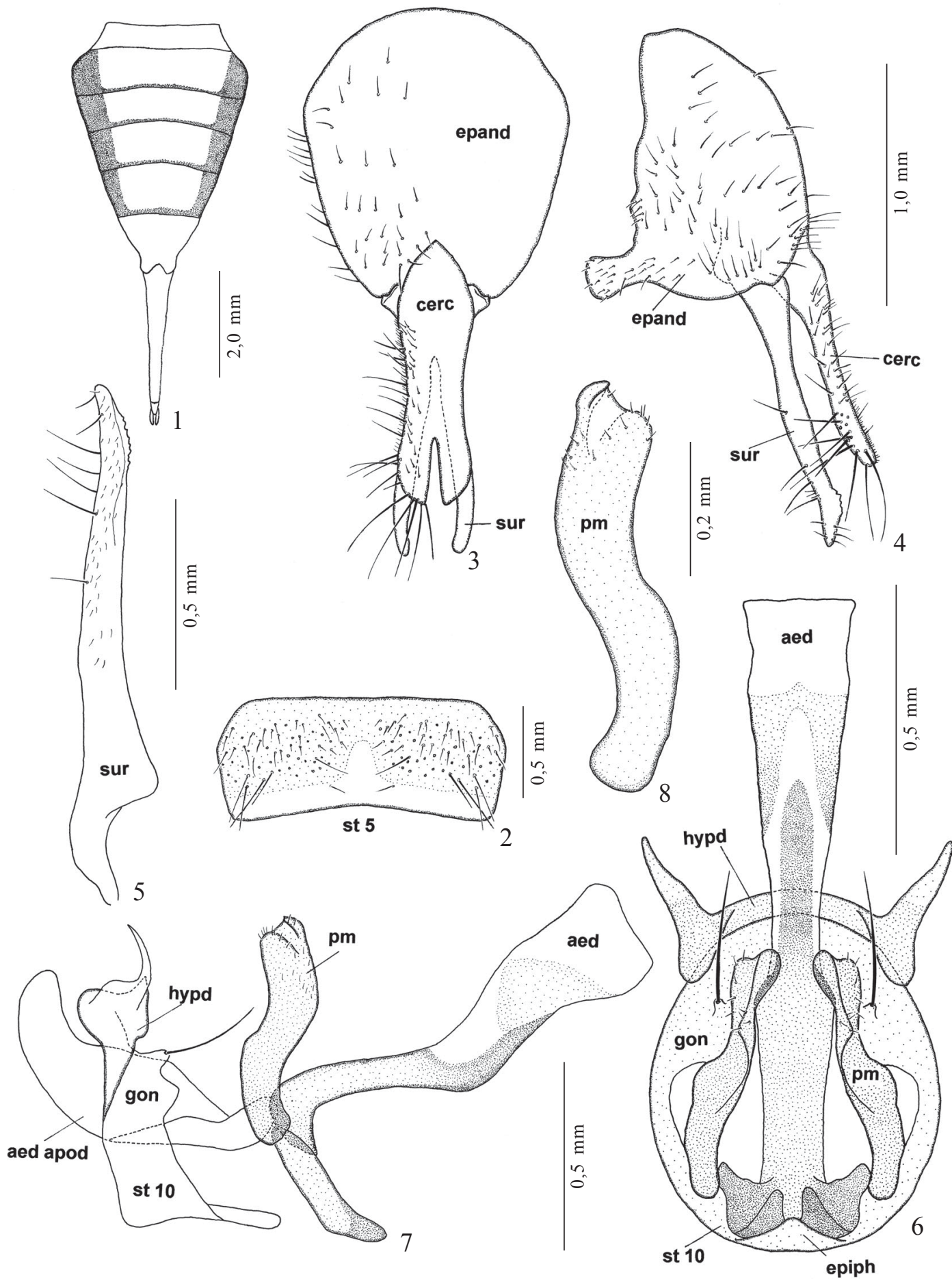

Figs. 1-8. Apophorhynchus amazonensis: 1 (fêmea), padrão de polinosidade do abdome (vista dorsal); 2-8 (macho): 2, esternito 5 (vista ventral); $3-4$, terminália masculina (vista ventral e lateral, mesma escala); 5, surstilo esquerdo (vista lateral); 6-7, terminália masculina interna (vista ventral e lateral); 8, parâmero esquerdo (vista lateral interna); aed = edeago; aed apod = apódema do edeago; cerc $=$ cerco; epan $=$ epândrio; epiph $=$ epifalo; gon = gonópodo; hypd $=$ hipândrio; $\mathrm{pm}=$ parâmero; st $=$ esternito; sur $=$ surstilo.

2(1). Esternito 6 com fileira de 5 cerdas espiniformes pósterolaterais (Fig. 17); face ventral do segmento 7 com 2 pares de cerdas no $1 / 5$ basal (1 par mediano e 1 par lateral) (Fig. 17)
Esternito 6 com fileira de 6 cerdas espiniformes pósterolaterais (Fig. 21); face ventral do segmento $7 \mathrm{com} 1$ par de cerdas mediano no $1 / 5$ basal (Fig. 21)

Apophorhynchus brevipenis sp. nov. 
Apophorhynchus amazonensis Prado, 1966

(Figs. 1-8, 16-19, 28)

Apophorhynchus amazonensis Prado, 1966: 248, 251-252 (chave, descrição da fêmea, ilustrações, distr. geográfica); 1967: 73-75 (descrição do macho, ilustrações, distr. geográfica); Steyskal, 1967: 1 (catálogo); Prado \& Papavero, 2002: 1 (catálogo).

Diagnose. Pernas amarelo-pálidas a castanho-claras nas fêmeas e castanhas nos machos; terminália feminina: tergito 6 com 4 cerdas póstero-laterais; esternito 6 com 5 cerdas espiniformes póstero-laterais; face ventral do segmento $7 \mathrm{com}$ 2 pares de cerdas no $1 / 5$ basal; espermateca com processo apical fino; terminália masculina: expansão póstero-lateral do epândrio reta; ápice do surstilo com margem lateral membranosa serrilhada; parâmero delgado, mais curto que $1 / 2$ do comprimento do edeago; edeago longo e delgado com projeções basais afiladas; tubérculo basal da cerda do gonópodo reduzido.

Fêmea. Comprimento do corpo: 8,6 mm. Comprimento e largura da asa: $7,8 \mathrm{~mm} \times 2,3 \mathrm{~mm}$.

Cabeça: fronte alaranjada; face e esclerito parafacial amarelados; tubérculo facial pontiagudo amarelo a castanhobrilhante; artículos antenais castanho-amarelados; arista castanho-alaranjada; polinosidade dourada entre e abaixo das antenas; clípeo castanho-brilhante; palpo amarelado com cerdas curtas, castanhas; gena amarelada com cerdas ruivas.

Tórax: escuto castanho, com as seguintes faixas de polinosidade dourada: 1 acrostical estreita e incompleta, limitando-se à região pré-sutural do escuto; 1 dorsocentral que se estende até o ápice do escutelo e 1 lateral estendendose do lóbulo pós-pronotal até o calo pós-alar; cerda dorsocentral pós-sutural pré-escutelar ausente. Escutelo castanho com 1 cerda apical e 1 subapical marginal; pleura castanha.

Asa: tégula com 2-3 cerdas destacadas; enfuscada, castanha, com veias castanho-escuras; medidas das seções da veia Costa : I 1,2 mm; II 1,8 mm; III 1,7 mm; IV 1,6 mm; V 1 $\mathrm{mm}$; VI $0,3 \mathrm{~mm}$.

Pernas: coxa anterior amarelada; coxas média e posterior castanhas, cobertas por polinosidade prateada esparsa; trocânteres amarelados; fêmures amarelados, com uma cerda ventral basal fina e longa. Fêmur anterior: face ventral com 58 cerdas espiniformes na $1 / 2$ apical da margem anterior; margem posterior com 8-10 cerdas, as 5-6 mais apicais espiniformes, as demais fracas. Fêmur médio: face ventral com 9-11 cerdas no $1 / 3$ apical da margem anterior e 6-9 cerdas na margem posterior. Fêmur posterior: face ventral com $9-12$ cerdas na $1 / 2$ apical da margem anterior e 6-8 na margem posterior. Tíbias amareladas; tíbia posterior com mancha castanha apical e basal, com 2-4 cerdas dorsais longas e finas. Tarsos com $1^{\circ}$ e $2^{\circ}$ tarsômeros cobertos por polinosidade esbranquiçada dorsal e intensa pilosidade dourada ventral; demais tarsômeros castanhoescuros.

Abdome: castanho-escuro, tergitos com polinosidade prateada. Terminália: tergito 6 esclerotinizado, principalmente nas laterais, cerdoso, com uma fileira de 4 cerdas na região póstero-lateral (Figs. 16, 18); esternito 6 com uma fileira de 5 cerdas espiniformes póstero-laterais (Figs. 17, 18); tergito 7 representado por uma placa cerdosa no $1 / 3$ basal, com a margem posterior reta (Fig. 16); face ventral do segmento 7 com 2 pares de cerdas no $1 / 5$ basal (1 par mediano e 1 lateral) (Fig. 17); espermateca com processo apical fino (Fig. 19).

Macho. Comprimento do corpo: $8,5 \mathrm{~mm}$. Comprimento e largura da asa: $6,5 \mathrm{~mm} \times 2 \mathrm{~mm}$.

Asa (Fig. 28); como na fêmea, exceto pelo que segue: medidas das seções da veia Costa: I 1mm; II 1,5 mm; III 1,8 mm; IV $1 \mathrm{~mm}$; V $1 \mathrm{~mm}$; VI 0,3 mm; coloração geral das pernas castanha. Fêmur anterior amarelado a castanho, com 4 cerdas curtas no $1 / 3$ apical das margens anterior e posterior da face ventral. Fêmur médio amarelado com polinosidade dourada nas faces anterior e ventral, castanho nas faces posterior e dorsal, ou inteiramente castanho; face ventral com 7-9 cerdas curtas na $1 / 2$ apical da margem anterior e $4-7$ cerdas na $1 / 2$ apical da margem posterior. Fêmur posterior dilatado, aproximadamente 2 vezes mais longo que largo; alaranjado a castanho-escuro; face ventral com 7-12 cerdas curtas na $1 / 2$ apical da margem anterior e 6-8 na $1 / 2$ apical da margem posterior. Tíbias anterior e média castanhas com áreas amareladas; tíbia posterior alaranjada a castanho-escura. Esternito 5 cerca de 3 vezes mais largo que longo (Fig. 2). Terminália: expansão póstero-lateral do epândrio reta, com borda truncada (Fig. 4); cerco longo, com ápice dilatado (Figs. 3-4); ápice do surstilo com margem lateral membranosa serrilhada (Figs. 4-5); parâmero delgado, mais curto que $1 / 2$ do comprimento do edeago (Figs. 6-7); edeago longo e delgado com projeções basais afiladas (Figs. 6-7); tubérculo basal da cerda do gonópodo reduzido (Figs. 6-7).

Distribuição geográfica. Brasil (Amazonas e Rondônia reg. nov.) e Peru (Loreto e Madre de Dios reg. nov.).

Material examinado. BRASIL, Amazonas, P[residente] Figueiredo, [?].1998, arm[adilha] McPhail [em] araçá, B. Ronchi-Teles leg., 1 fêmea (INPA); Manaus, INPA [Instituto Nacional de Pesquisas da Amazônia] Sede, Campus I, 13.iii.2003, arm[adilha] de garrafa Pet [McPhail modificada], N. C. Silva-Júnior leg., 1 fêmea (MPEG);

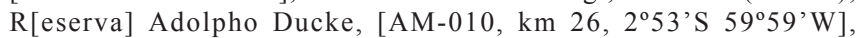
16.ix.2002, arm[adilha] McPhail [com solução aquosa de melaço de cana a $10 \%$ ], mata, platô, E. F. Soares \& A. L. Pinheiro leg., 1 fêmea (INPA); ibidem, área aberta, platô, 1 fêmea (MZSP); ibidem, 29.x.2002, 1 macho (INPA); ibidem, 19.ii.2003, 1 fêmea (MZSP); ibidem, 15.i.2003, área aberta, baixio, 1 fêmea (MPEG); E[scola] A[grícola] R[ainha dos] A[póstolos], BR-174, km 23, 28.v.1997, McPhail [com solução aquosa de melaço de cana a $10 \%$ ], em araticum, B. Ronchi-Teles leg., 1 macho (INPA); Manacapuru, viii.1997, arm[adilha] McPhail, B. Ronchi-Teles leg., 2 fêmeas (INPA); ibidem, ii.1998, 2 fêmeas e 2 machos (INPA), 2 fêmeas (MZSP) e 2 fêmeas (MPEG); [Rondônia $]$, Abunã, Rio Madeira, [sem data], Collection C. W. Johnson, Mann \& Baker leg., 1 macho (MCZ); PERU, Madre de Dios, Manu, Rio Manu, Pakitza, Aguajal, 19.ix.1988, A. Freidberg leg.,

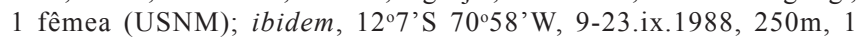
macho (USNM).

Variações. Artículos antenais, esclerito parafacial e gena 


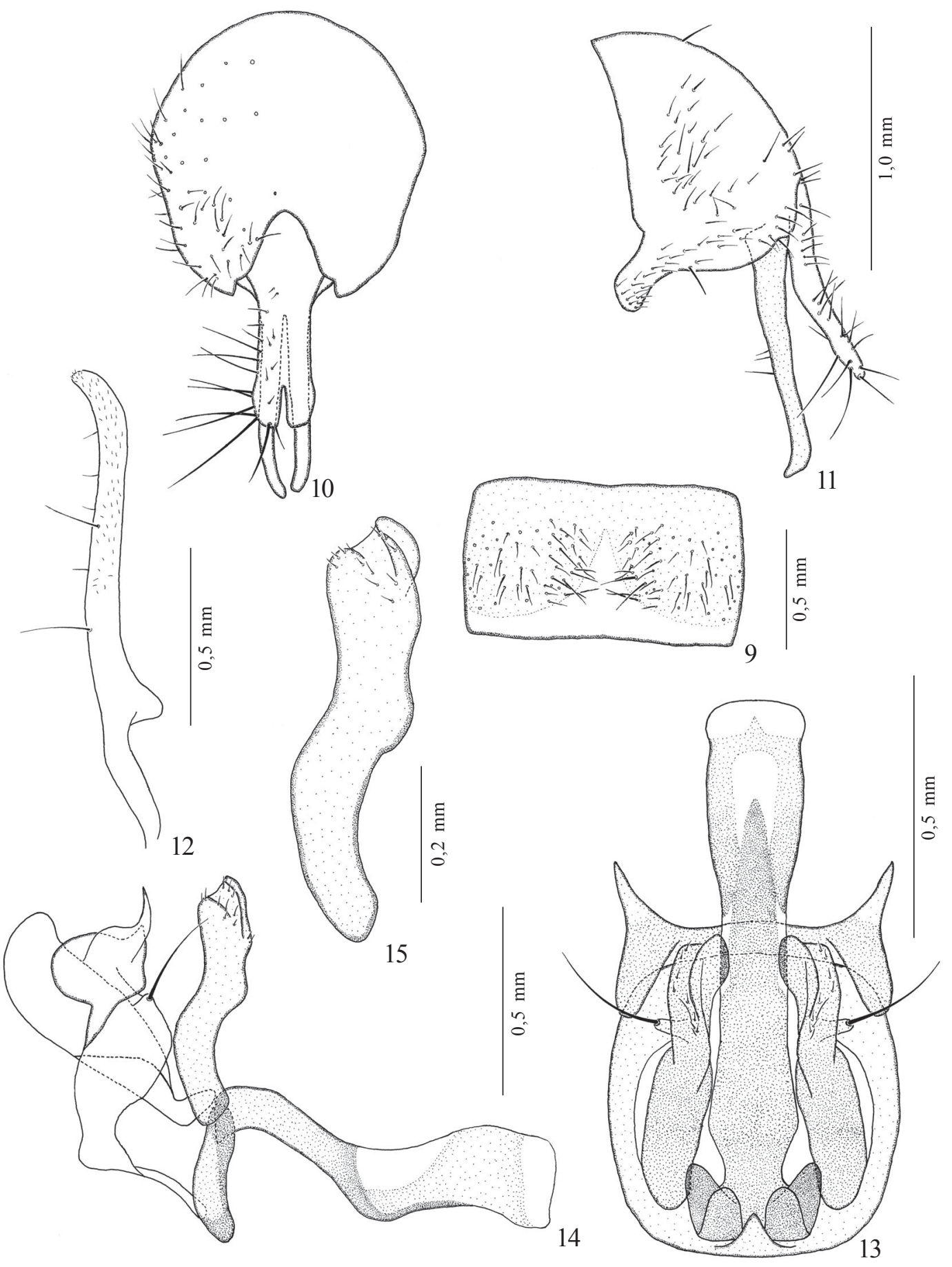

Figs. 9-15. Apophorhynchus brevipenis sp. nov. (parátipo macho): 9, esternito 5 (vista ventral); 10-11, terminália masculina (vista ventral e lateral, mesma escala); 12, surstilo esquerdo (vista lateral); 13-14, terminália masculina interna (vista ventral e lateral); 15, parâmero direito (vista lateral externa).

amarelos a castanhos; clípeo amarelo a castanho-brilhante; palpo amarelado a alaranjado; 1 cerda dorsocentral pós-sutural pré-escutelar presente em alguns exemplares; pleura castanha a castanho-escura. Grande variação no número e disposição das cerdas escutelares, principalmente nas fêmeas: escutelo com apenas o par de cerdas apical, sem cerdas subapicais; 1 par de cerdas apical e 1 cerda subapical no lado direito do corpo; 1 cerda subapical reduzida extranumerária do lado direito. Catepisterno com 1 cerda extranumerária no lado esquerdo. Fêmur posterior com mancha castanho-escura no ápice; tíbias anterior e média com manchas castanho-escuras; tíbia posterior sem manchas castanhas apical e basal; número de cerdas das pernas variável, mas sempre com o mesmo padrão de distribuição; um macho, proveniente de Rondônia, 
apresentou-se mais claro na coloração geral, tendo sido, por isso, identificado incorretamente como A. flavidus, embora o macho daquela espécie ainda não seja conhecido. Foram observados 1 macho e 1 fêmea coletados no Peru, que apresentaram as seguintes variações (provavelmente variações geográficas): pernas inteiramente castanhas; terminália feminina: tergito $7 \mathrm{com}$ placa um pouco mais alargada que nas demais fêmeas; esternito $6 \mathrm{com} 5$ cerdas espiniformes pósterolaterais e 1 cerda mais fraca mediana, ao lado da cerda espiniforme mais interna. Terminália masculina: cerco sem ápice dilatado; projeções basais do edeago mais engrossadas.

Discussão. As fêmeas desta espécie podem ser facilmente separadas das demais pela morfologia da terminália feminina, que difere principalmente pelo esternito 6 menos cerdoso e formato do tergito 7. Além disso, a face ventral do segmento 7 possui dois pares de cerdas, enquanto que nas outras espécies há apenas um. A terminália masculina também é facilmente reconhecida pelo seu aspecto geral mais delgado, se comparada a de $A$. brevipenis sp. nov. As estruturas, como um todo (cerco, surstilo, hipândrio, edeago e parâmero), são mais longas e delgadas.

Observação: A espécie A. amazonensis foi descrita de São Gabriel da Cachoeira, Amazonas, Brasil, a partir de uma única fêmea. De acordo com Prado (1966), o holótipo foi depositado no Instituto Oswaldo Cruz, Rio de Janeiro, Brasil, (IOC), mas não pôde ser localizado nesta instuição. Entretanto, segundo a curadora da Coleção Entomológica do IOC, Dr. Jane Costa (com. pesssoal), este tipo não está perdido, apenas não pôde ser localizado naquela instituição, sendo necessária uma busca mais acurada. Por este motivo, não coube designar um neótipo.

\section{Apophorhynchus brevipenis sp. nov.} (Figs. 9-15, 20-23, 29)

Diagnose. Pernas com coloração predominante castanha, mas com diferentes padrões de manchas amareladas a alaranjadas nos segmentos (principalmente nos fêmures); terminália feminina: tergito 6 com 7 cerdas finas pósterolaterais; esternito 6 com 6 cerdas espiniformes póstero-laterais; espermateca com processo apical fino; terminália masculina: expansão póstero-lateral do epândrio dirigida para a frente; surstilo sem margem lateral membranosa serrilhada; parâmero engrossado, ultrapassando $1 / 2$ do comprimento do edeago; edeago curto e moderadamente engrossado, com projeções basais arredondadas; tubérculo basal da cerda do gonópodo desenvolvido.

Holótipo macho. Comprimento do corpo: 7,9 mm. Comprimento e largura da asa: $6,8 \mathrm{~mm} \times 2 \mathrm{~mm}$.

Cabeça: fronte castanha com a margem anterior amarelada; face, tubérculo facial e esclerito parafacial amarelados; artículos antenais amarelados; flagelo com a margem dorsal castanha; arista com o $1 / 4$ basal amarelado, o restante castanho; polinosidade dourada entre e abaixo das antenas; clípeo castanho-brilhante; palpo amarelado com cerdas curtas ruivas e castanhas, principalmente no ápice; gena amarelada com cerdas ruivas.

Tórax: escuto castanho-escuro, com as seguintes faixas de polinosidade dourada: 1 acrostical estreita e incompleta, limitando-se à região pré-sutural do escuto; 1 dorsocentral que estende-se até o ápice do escutelo e 1 lateral estendendose do lóbulo pós-pronotal até o calo pós-alar; cerda dorsocentral pós-sutural pré-escutelar ausente. Escutelo castanho-escuro com 1 cerda apical e 1 subapical marginal; 1 cerda subapical reduzida extranumerária no lado direito do escutelo, entre as outras 2 cerdas; pleura castanho-escura.

Asa (Fig. 29): tégula com 3 cerdas destacadas; enfuscada, castanha; medidas das seções da veia Costa : I 1,0 mm; II 1,5 mm; III 1,7 mm; IV 1,2 mm; V 1,0 mm; VI 0,3 mm.

Pernas: coxas cobertas por polinosidade prateada esparsa e cerdas ruivas; coxa anterior castanho-escura na $1 / 2$ basal, o restante amarelado; coxa média e posterior castanho-escuras; trocânteres amarelados, o posterior castanho dorsalmente. Fêmur anterior: face dorsal castanha na base, o restante alaranjado, com cerdas distribuídas irregularmente e polinosidade dourada esparsa, face anterior castanho-escura e face posterior alaranjada com polinosidade dourada na $1 / 2$ basal; face ventral amarelada com 1 fileira de 4 cerdas fortes na $1 / 2$ apical da margem anterior, seguida por 1 cerda castanha longa e fina e várias cerdas ruivas finas e longas na $1 / 2$ basal; margem posterior com 4-5 cerdas destacadas na $1 / 2$ apical. Fêmur médio: faces posterior e dorsal castanho-escuras; faces anterior e ventral amareladas; polinosidade esparsa em todas as faces, exceto na posterior; face ventral com 1 fileira de 9-10 cerdas curtas e grossas nos $2 / 3$ apicais da margem anterior, margem posterior com 1 fileira de 6 cerdas na $1 / 2$ apical, 5 delas curtas e grossas, a mais basal castanha, longa e fina. Fêmur posterior aproximadamente 3 vezes mais longo que largo, castanho-escuro a negro; faces dorsal e ventral com manchas amareladas basalmente; faces anterior e dorsal com polinosidade esparsa; margem anterior da face ventral com 89 cerdas curtas e grossas na $1 / 2$ apical, seguidas de $1-2$ cerdas longas e finas próximo à base, e várias cerdas ruivas no $1 / 3$ basal. Tíbia anterior: ápice amarelado e face dorsal amarelada, o restante castanho-escuro; mancha alaranjada com intensa pilosidade de reflexos dourados no ápice da face posterior. Tíbia média castanho-escura, com ápice amarelado, 2 cerdas apicais ventrais. Tíbia posterior: mesma cor da tíbia média, com pequena mancha alaranjada apical na face ventral, 1-2 cerdas dorsais. Tarsos com polinosidade esbranquiçada nas faces dorsal e anterior do $1^{\circ}$ e $2^{\circ}$ tarsômeros; tarsos anterior e posterior com intensa pilosidade dourada nas faces ventral e posterior, restrita à base no tarso médio; demais tarsômeros castanhos.

Abdome: castanho-escuro, polinosidade dos tergitos prateada; esternito 5 cerca de 2 vezes mais largo que longo (Fig. 9). Terminália: expansão póstero-lateral do epândrio com bordo arredondado e levemente curvado para frente (Fig. 11); cerco longo (Figs. 10-11); surstilo sem margem lateral membranosa serrilhada (Figs. 11-12); parâmero robusto, ultrapassando $1 / 2$ do comprimento do edeago (Figs. 13-14); 

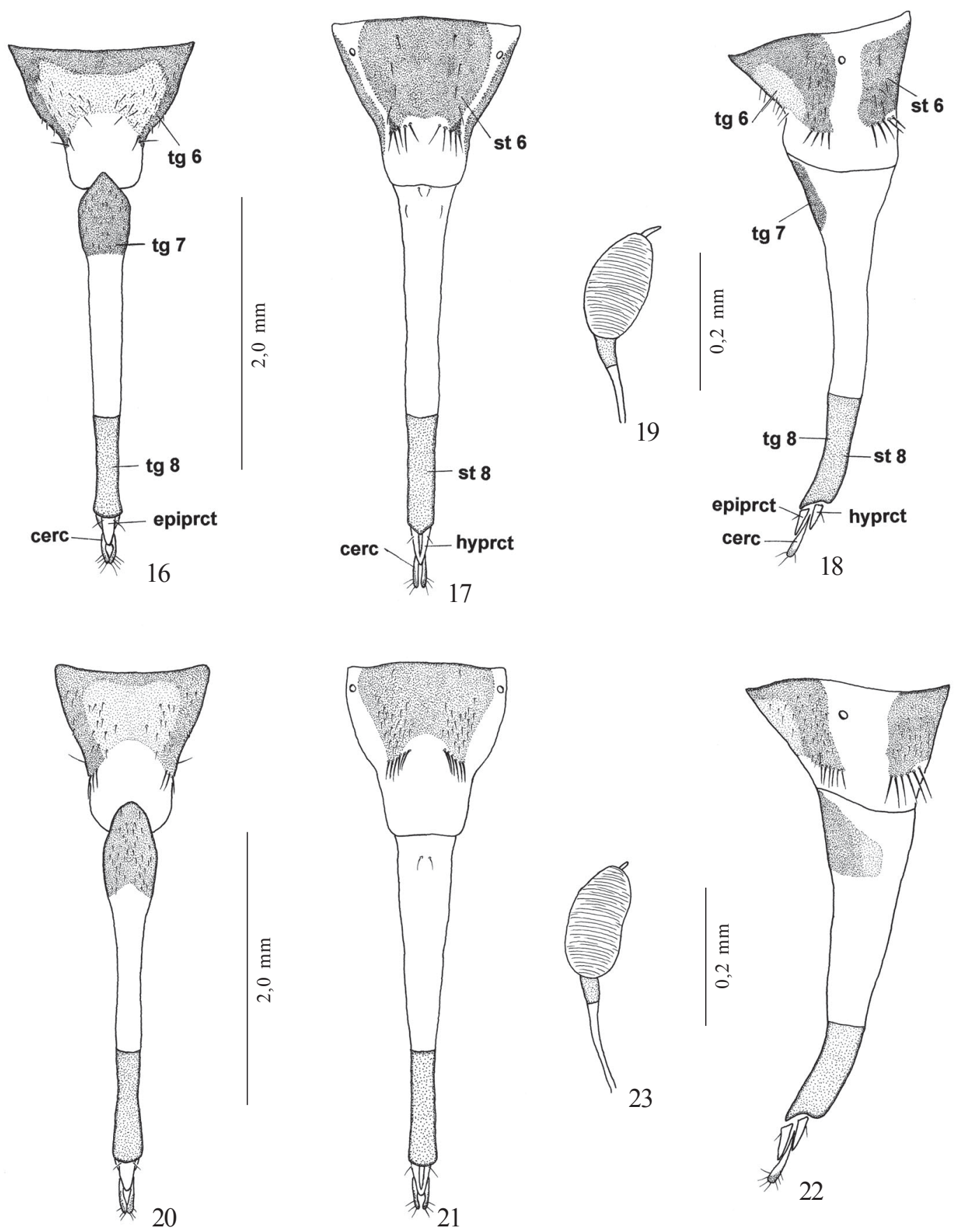

Figs. 16-23. Terminália feminina (vista dorsal, ventral e lateral direita) e espermateca: 16-19, Apophorhynchus amazonensis; 20-23, A brevipenis sp. nov. (parátipo); 16-18 e 20-22 na mesma escala; cerc = cerco; epiprct = epiprocto; hyprct $=$ hipoprocto; $\mathrm{st}=\mathrm{esternito}$; $\mathrm{tg}=$ tergito.

edeago curto e engrossado, com projeções basais arredondadas (Fig. 13-14); tubérculo basal da cerda do gonópodo desenvolvido (Figs. 13-14).

Fêmea. Comprimento do corpo: $8,4 \mathrm{~mm}$. Comprimento e largura da asa: 7,9 $\mathrm{mm} \times 2 \mathrm{~mm}$.

Como no macho, exceto pelo que segue: fronte de coloração mais clara, alaranjada, que se estende aproximadamente até a porção média, não estando restrita à margem anterior como nos machos; o restante da fronte escurecido, castanhoavermelhado a castanho-escuro; muitas vezes, a fronte apresenta-se quase que inteiramente alaranjada; tubérculo facial brilhante, amarelo ou castanho; flagelo castanho com 1 cerda dorsocentral reduzida presente ou não; 1-2 pós-pronotais fracas presentes ou não (quando 2, a interna é mais reduzida); medidas das seções da veia Costa: I 1,3 mm; II 1,9 mm; III 1,5 $\mathrm{mm}$; IV 2,0 mm; V 1,0 mm; VI 0,3 mm. Terminália: tergito 6 esclerotinizado, principlamente nas laterais, cerdoso, com uma 

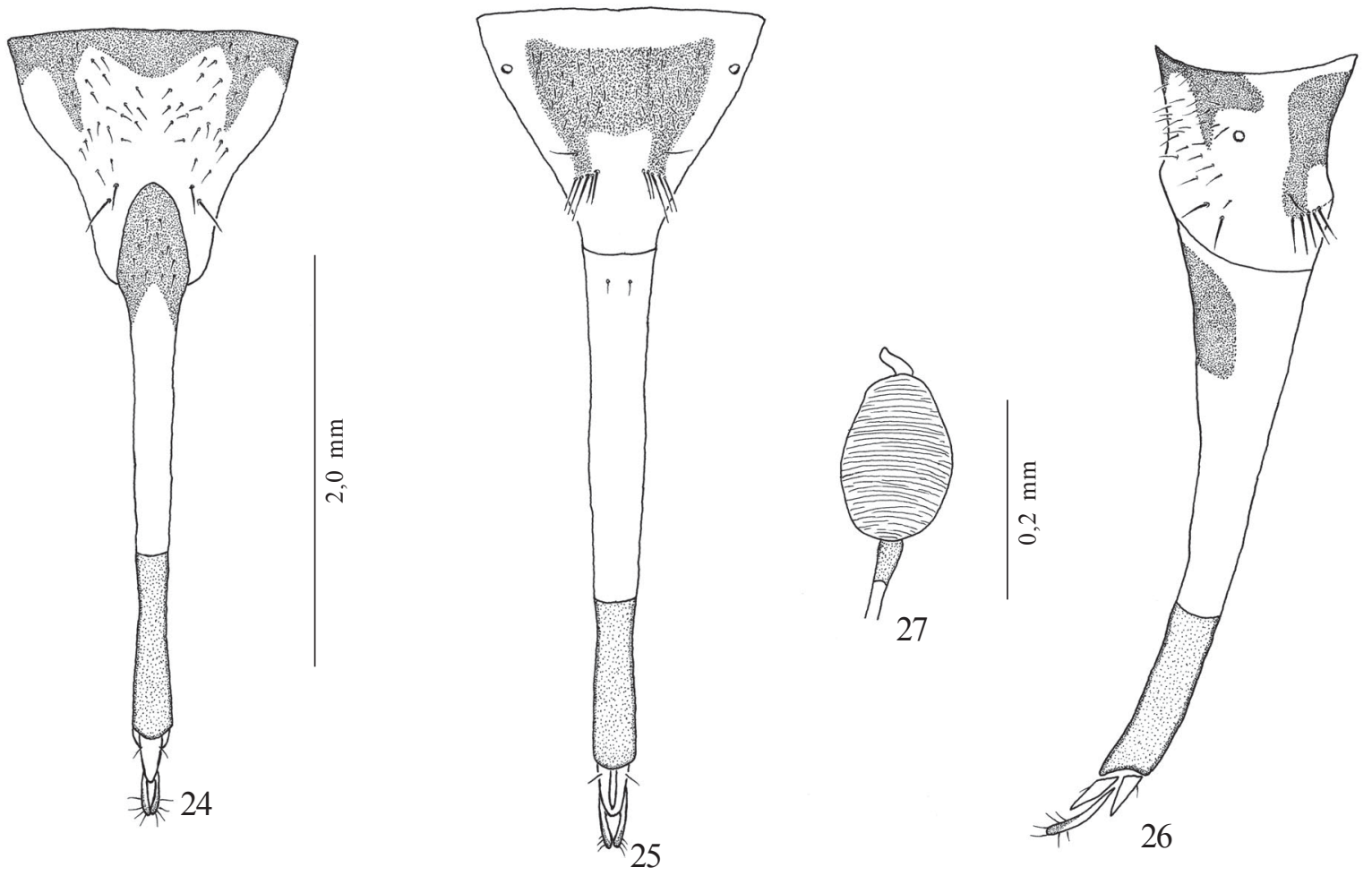

Figs. 24-27. Terminália feminina (vista dorsal, ventral e lateral direita) e espermateca: Apophorhynchus flavidus; 24-26 na mesma escala.

fileira de 7 cerdas finas na região póstero-lateral (Figs. 20, 22); esternito 6 com uma fileira de 6 cerdas espiniformes pósterolaterais (Figs. 21, 22); tergito 7 representado por uma placa cerdosa no $1 /$, basal, com uma pequena reentrância na margem posterior (Fig. 20); segmento 7 com 1 par de cerdas ventral mediano no $1 / 5$ basal (Fig. 21); espermateca com processo apical fino (Fig. 23).

\section{Distribuição geográfica. Brasil (Amazonas).}

Material-tipo examinado. Holótipo macho (INPA), etiquetado: BRASIL, Amazonas, Manaus, R[eserva] [Adolpho] Ducke, [AM-010,

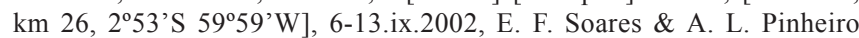
leg. (etiqueta impressa branca)/ arm[adilha] McPhail [com solução aquosa de melaço de cana a 10\%], mata, baixio, Ig[arapé] Barro Branco (etiqueta impressa branca)/ Holótipo, Apophorhynchus brevipenis, Marques \& Ale-Rocha (etiqueta impressa vermelha). Condição do holótipo: em perfeito estado de conservação; abdome dissecado a partir do $1^{\circ}$ segmento, acondicionado em microtubo com glicerina, afixado no alfinete do espécime.

Parátipos. BRASIL, Amazonas, Manaus, R[eserva] [Adolpho]

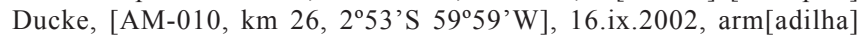
McPhail [com solução aquosa de melaço de cana a 10\%], mata, baixio, Ig[arapé] Barro Branco, E. F. Soares \& A. L. Pinheiro leg., 1 macho e 3 fêmeas (INPA); ibidem, 16.x.2002, 1 fêmea (MZSP); ibidem, 15.i.[20]03, 1 fêmea (MZSP); ibidem, 10.ix.2002, área aberta, platô, 1 fêmea (MZSP); ibidem, 2-9.x.2002, 1 fêmea (MPEG); ibidem, 24.vii.2003, área aberta, baixio, 1 fêmea (MPEG); E[stação] E[xperimental] [de] F[ruticultura] T[ropical], BR-174, Km 40, 06.iii.1997, McPhail em camu-camu, B. Ronchi-Teles leg., 1 fêmea (INPA); ibidem, 09.x.1997, em sorva, 1 fêmea (INPA); Sítio Vida Tropical, R[amal] Água Branca II, AM-010, Km 35, 13.ii.1997, McPhail em goiaba-de-anta, B. Ronchi-Teles leg., 1 fêmea (INPA); Presidente
Figueiredo, AM-240, Km 24, Com[unidade] S[ão] F[rancis]co de Assis, $02^{\circ} 01^{\prime} \mathrm{S} 59^{\circ} 49^{\prime} \mathrm{W}, 01-11 . i x .2002$, isca de banana fermentada, F. Xavier \& U. [C.] Barbosa leg., 1 macho e 2 fêmeas (INPA) (todos os parátipos com etiquetas de identificação impressas amarelas).

Variações. Margem anterior da fronte amarelada a alaranjada; artículos antenais alaranjados; esclerito parafacial e gena amarelados a castanho-escuros; clípeo amarelo a castanho- brilhante; 1 -2 cerdas pós-pronotais fracas, presentes ou não (principalmente nas fêmeas), sendo que um macho apresentou este caráter; é comum a ocorrência de uma cerda extranumerária reduzida entre o par apical e subapical do escutelo, em um ou ambos os lados do escutelo (característica observada em machos e fêmeas); ausência de mancha alaranjada apical na face ventral da tíbia posterior e 1-4 cerdas dorsais; número de cerdas das pernas bastante variável, mas sempre com o mesmo padrão de distribuição.

Comentários. As fêmeas desta espécie podem ser facilmente separadas das demais, pela coloração das pernas, com a cor castanha predominante, enquanto que nas outras espécies as pernas das fêmeas são amareladas. A terminália feminina difere pelo número de cerdas do tergito 6 ( 7 cerdas finas póstero-laterais) e esternito 6 (6 cerdas espiniformes póstero-laterais). A espermateca é muito semelhante à de $A$. amazonensis, diferindo somente no processo apical que é mais curto em $A$. brevipenis sp. nov. A terminália masculina distingue-se facilmente por apresentar praticamente todas as estruturas menores e mais robustas que em A. amazonensis. $\mathrm{O}$ cerco é mais curto, o surstilo não possui margem lateral 
membranosa serrilhada, o parâmero é mais engrossado e o edeago também é mais curto e grosso.

Etimologia. Do Latim, brevi= curto e penis= pênis, referindose ao menor tamanho do edeago desta espécie em relação ao de A. amazonensis.

\section{Apophorhynchus flavidus Williston, 1895}

(Figs. 24-27,30)

Apophorhynchus flavidus Williston, 1895: 184, 186-187 (chave, descrição da fêmea); Lindner, 1930: 129 (redescrição); Malloch, 1941: 50 (redescrição); Prado, 1966: 248, 249-251 (chave, redescrição, ilustrações, distr. geográfica); Steyskal, 1967: 1 (catálogo).

Diagnose. coloração geral amarelada; pernas amareladas e brilhantes; abdome castanho com polinosidade dourada; terminália feminina: tergito 6 cerdoso, esclerotinizado na margem anterior, com 1-2 cerdas maiores na região pósterolateral; esternito 6 com fileira de 5 cerdas espiniformes pósterolaterais e 1 cerda destacada anterior a estas; espermateca com processo apical grosso.

Fêmea. Comprimento do corpo: $8,6 \mathrm{~mm}$. Comprimento e largura da asa: 7,1 $\mathrm{mm}$ x 2,0 $\mathrm{mm}$.

Cabeça: fronte e artículos antenais alaranjados; arista amarelada no $1 / 4$ basal, o restante alaranjado; face e clípeo amarelados, brilhantes; tubérculo facial castanho-brilhante; polinosidade prateada entre e abaixo das antenas; esclerito parafacial amarelado; gena e palpo amarelados, com cerdas ruivas.

Tórax: escuto castanho, com as seguintes faixas de polinosidade dourada: 1 acrostical estreita e incompleta, limitando-se à região pré-sutural do escuto; 1 dorsocentral que se estende até o ápice do escutelo e 1 lateral estendendose do lóbulo pós-pronotal até o calo pós-alar; 1 cerda dorsocentral pós-sutural pré-escutelar reduzida; Escutelo castanho, com 1 cerda apical e 1 subapical marginal; pleura castanha, sem brilho.

Asa (Fig. 30): tégula com 2 cerdas destacadas; uniformemente amarelada; veias castanho-claras à alaranjadas; medidas das seções da veia Costa: I 1,0 mm; II 1,7 mm; III 1,5 $\mathrm{mm}$; IV 1,7 mm; V 0,7 mm; VI 0,3 mm.

Pernas: coxa anterior amarelada; coxa média castanha e a posterior amarelada dorsalmente, o restante castanho; trocânteres amarelados. Fêmur anterior: face dorsal com cerdas finas na $1 / 2$ apical; face ventral com 6-8 cerdas espiniformes na $1 / 2$ apical da margem anterior e 6-7 cerdas na margem posterior. Fêmur médio: $2 / 3$ apicais da face ventral com 9 cerdas espiniformes na margem anterior e 7-9 na margem posterior. Fêmur posterior inteiramente amarelo, alargado; face dorsal com várias cerdas longas e finas e, em série, nos $2 / 3$ basais; face ventral com fileira de 9-11 cerdas curtas e grossas na $1 / 2$ apical da margem anterior e 6-8 cerdas grossas na margem posterior. Tíbias delgadas, amareladas e brilhantes; tíbia anterior com 1 cerda subapical dorsal destacada; tíbia média
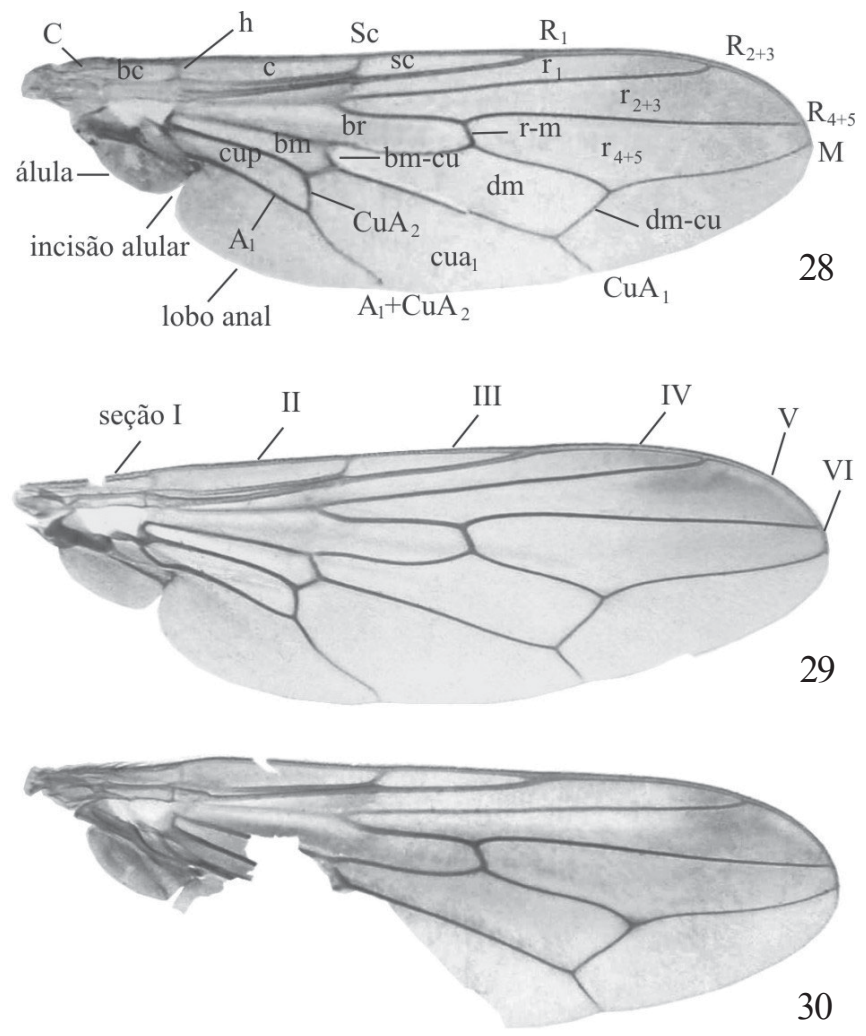

Figs. 28-30. Asas: 28, Apophorhynchus amazonensis (macho); 29, Apophorhynchus brevipenis sp. nov. (parátipo macho); 30, Apophorhynchus flavidus (fêmea).

com 2 cerdas apicais grossas ventrais; tíbia posterior com pequena mancha castanha apical na face anterior e posterior e anel castanho na base, 2-3 cerdas dorsais longas e finas. Tarsos com $1^{\circ}-3^{\circ}$ tarsômeros amarelados, com intensa pilosidade ruiva ventral e posterior; demais tarsômeros castanhos.

Abdome: castanho-escuro, com polinosidade dos tergitos dourada. Terminália: tergito 6 cerdoso, esclerotinizado na margem anterior, com 1-2 cerdas maiores na região pósterolateral (Figs. 24, 26); esternito 6 também cerdoso, com uma fileira de 5 cerdas espiniformes posteriormente e 1 cerda destacada anterior a estas (Figs. 25, 26); tergito 7 representado por uma placa cerdosa no $1 \frac{1}{3}$ basal, com reentrância na margem posterior (Fig. 24); face ventral do segmento 7 membranosa com 1 par de cerdas medianas no $1 /{ }_{5}$ basal (Fig. 25); espermateca com processo apical grosso (Fig. 27).

Macho. Desconhecido.

Distribuição geográfica. Brasil (Mato Grosso) e Bolívia (Santa Cruz).

Material-tipo examinado. Síntipo fêmea (AMNH), etiquetado: [BRASIL, Mato Grosso] Chapada [dos Guimarães, sem data, coletor anônimo], Am[erican] Mus[eum of] Nat[ural] Hist[ory], Depart. Invert. Zoology, No 20359 .

Observação: O síntipo de A. flavidus encontra-se no 
"American Museum of Natural History" (AMNH). Entretanto, não foi possível realizar o empréstimo deste espécime. A redescrição de $A$. flavidus foi feita com base na descrição original, observação de fotos do síntipo e análise de dois espécimes previamente identificados. Como o síntipo foi observado apenas através de fotos e não se teve acesso ao mesmo, este não pôde ser designado lectótipo. Condição do síntipo: em perfeito estado de conservação, não dissecado.

Material examinado. BRASIL, Mato Grosso, Cuiabá, vii-ix.[1]934, [espécime sem abdome], nº 333A, J. Lane leg., 1 fêmea (MZSP); BOLÍviA, [Santa Cruz], Prov[íncia] Sara, [sem data], Steia Vach leg., 1 fêmea (MCZ).

Variações. Fronte amarelada a alaranjada; artículos antenais amarelos, alaranjados ou castanhos; face e clípeo brilhantes, amarelos a castanhos; tubérculo facial da mesma cor da face; esclerito parafacial e gena amarelos a castanho-claros; palpo castanho-claro com cerdas castanhas e/ou ruivas; cerda dorsocentral pós-sutural pré escutelar ausente; uma fêmea apresentou 1 dorsocentral reduzida, situada anteriormente à intra-pós-alar, somente no lado direito do escuto; escutelo somente com o par de cerdas apicais; tíbias anterior, média e posterior podendo apresentar manchas castanhas.

Discussão. Apophorhynchus flavidus pode ser facilmente separada das demais espécies do gênero pela coloração amarelada e pela polinosidade dourada do abdome. O macho desta espécie é desconhecido, enquanto que a terminália feminina assemelha-se a de $A$. brevipenis sp. nov., diferindo pelo formato e número de cerdas póstero-laterais do tergito 6 , pela presença de 1 cerda destacada anteriormente às cerdas póstero-laterais do esternito 6 e pela forma da espermateca, que possui processo apical grosso.

Agradecimentos. Ao Dr. José Albertino Rafael/ Dr. Augusto L. Henriques (INPA), Dr. Orlando Tobias Silveira/ Dra. Ana Yoshi Harada (MPEG), Dra. Sônia Casari (MZSP), Dr. Philip D. Perkins (MCZ) e Dr. Allen L. Norrbom (USNM) pelo empréstimo dos espécimes; ao Dr. David Grimaldi e Dr. Tam C. Nguyen (AMNH) pelas fotos do síntipo de
A. flavidus; aos revisores, entre eles o Dr. Silvio Nihei (MZSP), pelas correções e sugestões e à Coordenação de Aperfeiçoamento de Pessoal de Nível Superior (CAPES) pela bolsa de mestrado concedida à primeira autora.

\section{REFERÊNCIAS}

Lindner, E. 1930. Revision der amerikanischen Dipteren-Familie der Rhopalomeridae. Deutsche Entomologische Zeitschrift 2: $122-137$.

Malloch, J. R. 1941. Florida Diptera. Family Rhopalomeridae. Florida Entomologist 24: 49-51.

McAlpine, J. F.; 1981. Morphology and terminology - Adults, p. 9-63. In: J. F. McAlpine (coord.). Manual of Nearctic Diptera. Vol. 1. Res. Branch Agr. Canada Monogr. 27.

Marques, A. P. C. \& R. Ale-Rocha. 2004. Revisão do gênero Kroeberia Lindner (Diptera, Ropalomeridae) da Região Neotropical. Revista Brasileira de Entomologia 48: 315-322.

Marques, A. P. C. \& R. Ale-Rocha. 2005. Revisão do gênero Willistoniella Mik, 1895 (Diptera, Ropalomeridae) da Região Neotropical. Revista Brasileira de Entomologia 49: 210-227.

Prado, A. P. 1966. Segunda contribuição ao conhecimento da família Rhopalomeridae (Diptera, Acalyptratae). Studia Entomologica 8 [1965]: 209-268.

Prado, A. P. 1967. Sobre alguns Ropalomeridae do American Museum of Natural History, New York (Diptera, Acalyptratae). Revista Brasileira de Biologia 27: 71-75.

Prado, A. P. \& N. Papavero. 2002. Insecta - Diptera - Ropalomeridae, p. 1-3. In: N. Papavero (ed.). Fauna da Amazônia Brasileira. Vol. 5. Museu Paraense Emílio Goeldi.

Ramírez-García, E. \& V. Hernández-Ortiz. 1994. Revisión de la familia Ropalomeridae (Diptera) en Mexico. Acta Zoologica Mexicana 61: $57-85$.

Steyskal, G. C. 1967. Family Ropalomeridae, p. 1-7. In: A catalogue of the Diptera of the Americas south of the United States. São Paulo, Departamento de Zoologia, Secretaria de Agricultura, v. 60 .

Steyskal, G. C. 1987. Ropalomeridae, p. 941-944. In: J. F. McAlpine, B. V. Peterson, G. E. Shewell, H. J. Teskey, J. R. Vockeroth \& D. M. Wood (eds.). Manual of Nearctic Diptera. Vol. 2. Res. Branch Agr. Canada Monogr. 28.

Williston, S. W. 1895. On the Rhopalomeridae. Psyche 7: 183-187. Williston, S. W. 1896. Manual of the families and genera of North American Diptera. 2nd. ed., New Haven, J. T. Hathaway, 167 pp. 